\title{
Making the blastocyst: lessons from the mouse
}

\author{
Katie Cockburn and Janet Rossant \\ Department of Molecular Genetics, University of Toronto, Canada. Program in Developmental and Stem Cell Biology, \\ Hospital for Sick Children Research Institute, MARS Building, Toronto Medical Discovery Tower, Canada.
}

\begin{abstract}
Mammalian preimplantation development, which is the period extending from fertilization to implantation, results in the formation of a blastocyst with three distinct cell lineages. Only one of these lineages, the epiblast, contributes to the embryo itself, while the other two lineages, the trophectoderm and the primitive endoderm, become extraembryonic tissues. Significant gains have been made in our understanding of the major events of mouse preimplantation development, and recent discoveries have shed new light on the establishment of the three blastocyst lineages. What is less clear, however, is how closely human preimplantation development mimics that in the mouse. A greater understanding of the similarities and differences between mouse and human preimplantation development has implications for improving assisted reproductive technologies and for deriving human embryonic stem cells.
\end{abstract}

\section{Introduction}

The period of preimplantation development in mammals, extending from egg fertilization to implantation of the blastocyst in the uterus, is a key stage during which the first three major cell lineages of the embryo and its extraembryonic membranes are set aside. These three lineages contribute to distinct tissues in later development: the epiblast (EPI) gives rise to the fetus itself; the trophectoderm (TE) goes on to form the majority of the fetal contribution to the placenta; and the primitive endoderm (PE) becomes the parietal and visceral endoderm, which later contributes to the yolk sac. Knowledge about how these lineages develop during the preimplantation period has major clinical implications for increasing the success of assisted reproductive strategies (ARTs) such as in vitro fertilization (IVF) and preimplantation genetic diagnosis (PGD), preventing the high rate of early pregnancy loss in humans, and improving the derivation of stem cell lines from human embryos.

Much of what we know about preimplantation development has come from studies in the mouse, which has been used as a model for the early human embryo for over 40 years. Here, we review what has been learned from the mouse about the major events of mammalian preimplantation development and discuss recent work that has shed new insight on how the three blastocyst lineages come to be established. Despite the significant progress that has been made, we still know little about how closely the events of preimplantation development in the mouse reflect the human situation. We compare between mouse and human development where possible and point out where more investigation of early human development could be especially worthwhile.

\section{Preimplantation development: an overview}

Early cleavage and zygotic genome activation. The fertilized egg first undergoes a series of early cleavage divisions, producing increasing numbers of progressively smaller cells, known as blastomeres, without changing the overall size of the embryo (Figure 1). As in other types of organisms, protein synthesis in the mammalian zygote initially relies on a deposit of maternally loaded mRNA (1). Transcription of mRNA coded by the zygotic genome begins during the first few cleavage divisions, and this transition from maternal to zygotic transcripts is known as zygotic genome activation (ZGA). ZGA takes place quite early in the mouse: there is an initial burst of

Conflict of interest: The authors have declared that no conflict of interest exists. Citation for this article: J Clin Invest. 2010;120(4):995-1003. doi:10.1172/JCI41229. zygotic transcription at the end of the one-cell stage, followed by a second, larger burst at the two-cell stage $(2,3)$. This second burst is accompanied by degradation of maternal transcripts $(4,5)$. In humans, ZGA occurs later than in the mouse, at the four- to eightcell stage (6). This is the first of several indications that the timing of events in human and mouse preimplantation development may differ. Although maternal mRNAs may be degraded, proteins that have been synthesized from these transcripts during oogenesis can persist into later development. The presence of such "maternal" proteins can confound the analysis of gene function during preimplantation development in mouse studies, often requiring the generation of maternal and zygotic loss-of-function mutants $(7,8)$. Given the difference in timing of ZGA between mice and humans, the relative roles of maternal and zygotic transcripts may be somewhat different in mouse and human embryos.

Compaction and polarization. The early cleavage divisions produce an eight-cell embryo that subsequently undergoes an increase in intercellular adhesion known as compaction, causing all cells to adopt a more flattened morphology (Figure 1). This process of compaction is essential for later morphogenetic events and for the proper segregation of the three embryonic lineages. In the mouse, compaction is associated with the formation of adherens and, later, tight junctions between cells. E-cadherin, a major component of adherens junctions, becomes localized to regions of cell-cell contact at the eight-cell stage (9), and disruption of E-cadherin-mediated cell adhesion, by removal of $\mathrm{Ca}^{2+}$ ions or addition of E-cadherinspecific antibodies to embryo culture media, inhibits compaction (10-12). E-cadherin-knockout embryos do compact normally at the eight-cell stage because of the presence of E-cadherin protein inherited from the egg, but they fail to maintain proper cell adhesion into the blastocyst stage $(7,8)$. Conversely, embryos deficient in the maternal supply of E-cadherin fail to compact at the eightcell stage, but they are rescued by zygotic expression of the paternal allele and compact by the 16-cell stage (13).

It remains unclear how the process of compaction is initiated. A simple increase in the level of expression of E-cadherin or its intracellular binding partners $\alpha$ - and $\beta$-catenin cannot account for the change, as all are present in the mouse embryo from fertilization onward $(9,14)$. In fact, compaction can occur even when mRNA synthesis is blocked from the early four-cell stage onward (15), and is actually induced prematurely by culturing four-cell-stage embryos in the presence of inhibitors of protein synthesis (16). This indicates that all the components required for 


\section{A Mouse}

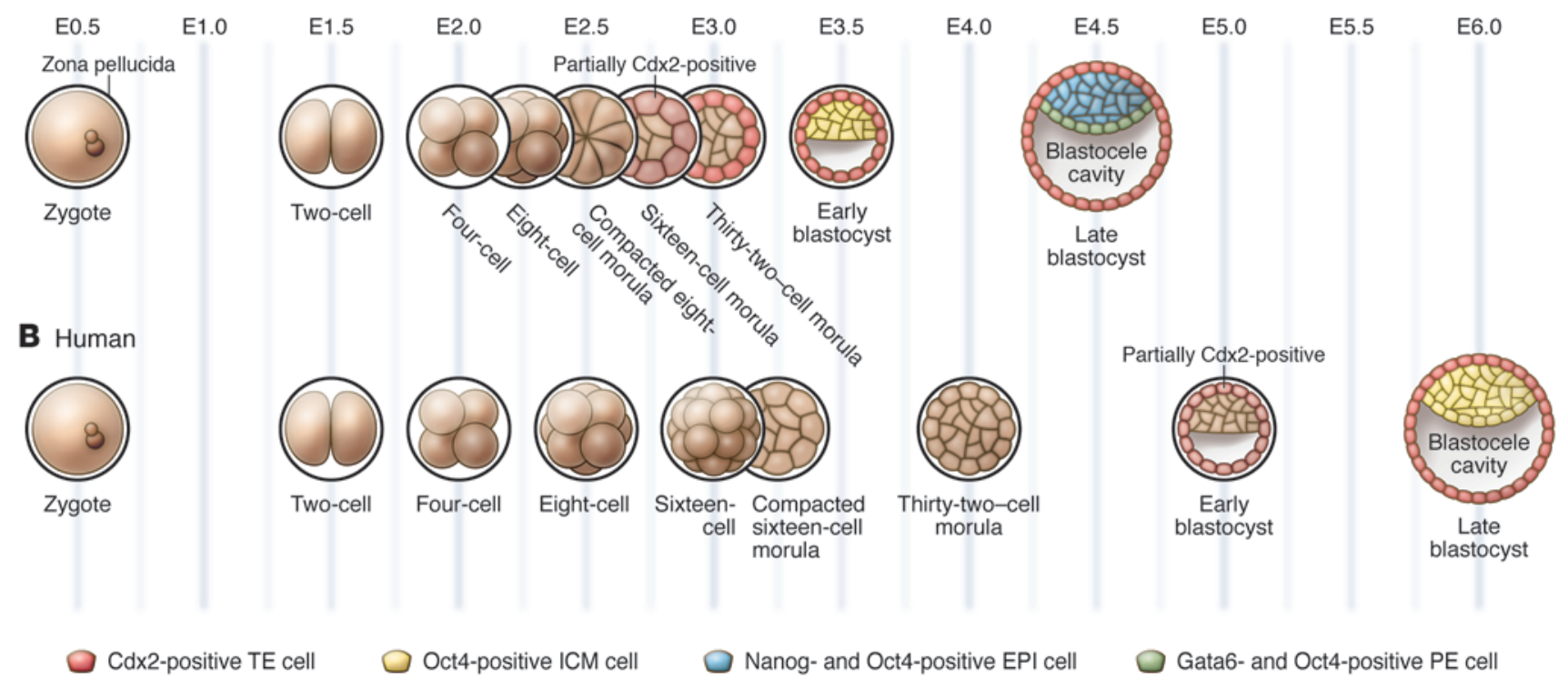

Figure 1

Stages of mouse and human preimplantation development. (A) In the mouse, the fertilized egg undergoes three rounds of cleavage, producing an eight-cell embryo that then undergoes compaction. From the eight-cell stage onward, cell divisions produce two populations of cells, those that occupy the inside of the embryo and those that are located on the outside. The blastocoel cavity begins to form inside the embryo beginning at the 32-cell stage and continues to expand as the embryo grows and matures into the late blastocyst stage. Cdx2 becomes upregulated in outside, future TE cells, starting at the 32-cell stage, while Oct4 expression becomes limited to the ICM in the early blastocyst stage. By the late blastocyst stage, while continuing to express Oct4 ubiquitously, the ICM contains a population of Nanog-positive EPI cells and a population of Gata6-positive PE cells. (B) Development is similar in the early human embryo, although compaction occurs at the 16-cell stage and the mutually exclusive expression patterns of CDX2 and OCT4 are not established until the late blastocyst stage. The expression patterns of NANOG and GATA6 in the human preimplantation embryo have not yet been characterized.

compaction have been synthesized by the time the embryo reaches the early four-cell stage. Notably, culture of embryos with small molecules that activate PKC also causes premature compaction $(17,18)$. This suggests that posttranslational mechanisms play an important role in the induction of compaction, possibly by maintaining the E-cadherin complex in an inactive state, although how this might occur remains to be elucidated. In support of this theory, both E-cadherin and $\beta$-catenin become phosphorylated at the time of compaction $(19,20)$. The Rho family GTPases also play a role in this process $(21,22)$. In cultured cells, IQ motif-containing GTPase-activating protein 1 (IQGAP1) can disrupt cadherin/ catenin complexes by preventing the binding of $\alpha$-catenin to $\beta$-catenin and E-cadherin until it is bound and inactivated by the Rho family GTPases Rac1 and Cdc42 (23). Changes in the subcellular distribution of IQGAP1 and Rac1 protein before and during compaction suggest that a similar relationship exists in the preimplantation mouse embryo (22). This has led to the hypothesis that IQGAP1 prevents premature compaction until the eight-cell stage, when Rac1 and Cdc42 are activated, although this has not yet been tested experimentally (24).

Blastomeres do not show any signs of intracellular polarity until compaction but, concomitant with the increase in cell adhesion at this stage, all cells rapidly polarize along the axis perpendicular to cell contact such that outward facing (apical) regions become distinct from inward facing (basolateral) regions (Figure 2). The cytoplasm becomes reorganized: cell nuclei move basolaterally (25), while the endosomes, previously distributed randomly, become localized apically (26). Actin accumulates apically, as do most microtubules, although a smaller population of more stable acetylated microtubules becomes localized basolaterally $(27,28)$. Microvilli that were equally distributed on the cell surface prior to compaction accumulate at the apical pole and are almost completely eliminated basolaterally (29). As is the case in other polarized cell types, the membrane protein ezrin (30), the polarity proteins Par3 and Par6 $(31,32)$, and atypical PKC (aPKC) (33) all become localized to the apical domain, while the polarity proteins Par1 and lethal giant larva homolog (Lgl) accumulate basolaterally (32).

It is unclear how polarization is initiated de novo at the eightcell stage. Based on the close temporal link between compaction and polarization, one hypothesis is that cell contact is somehow important for the establishment of the apical and basolateral domains. Multiple studies have shown that cellular interactions are involved in setting up the orientation of polarity, as apical poles tend to form in positions that are as far away as possible from locations of cell contact $(34,35)$. However, polarization can occur in blastomeres that have been isolated from cell contact or prevented from compacting, albeit at a lower frequency than usual $(36,37)$. Thus it appears that cell contact is partially responsible for the establishment of polarity but that there are other mechanisms involved, one of which is dependent on nucleus-microtubule-cortex interactions $(32,36)$. Regardless of how polarity is established, it is likely maintained, as in other systems, by the mutual antagonism of apical and basal protein complexes containing the various PAR proteins, aPKC, and $\mathrm{Lgl}$ (38). 


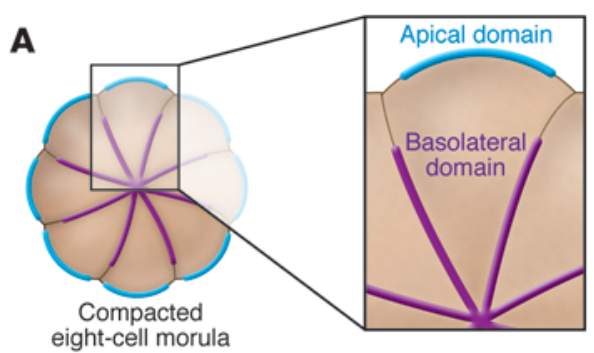

B

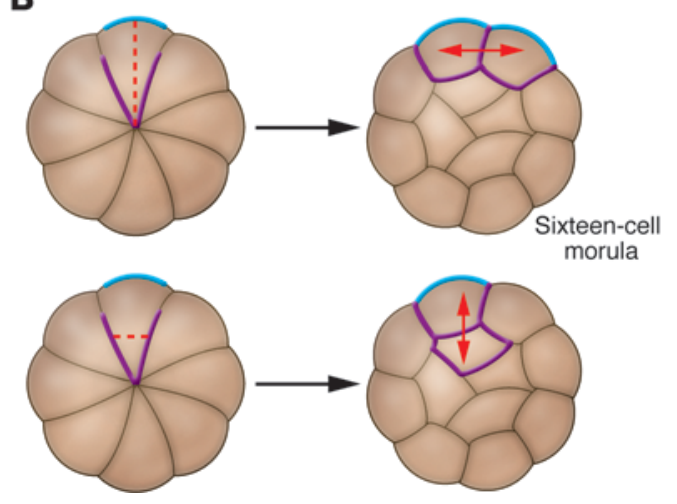

Symmetric versus asymmetric cell divisions up to the 32-cell stage. Once the eight-cell embryo has compacted and polarized, it undergoes two further rounds of cleavage, growing from eight cells to 16 , and from 16 cells to 32 . During these divisions, inheritance of the polarized state is influenced by the orientation of the cleavage plane of the blastomere (Figure 2). If a cell undergoes mitosis at an angle perpendicular to its axis of polarity (that is, parallel to its inside-outside axis), its two daughter cells will both be polar and will remain on the outside of the embryo. However, cells can also divide parallel to their axis of polarity, producing one polarized outside daughter cell and one apolar cell that is located on the inside of the embryo $(39,40)$. In this way the preimplantation embryo, which was previously composed of a uniform population of cells, has now generated two separate groups of cells: apolar inside cells and polar outside cells. Cell polarity and cell position are both important in defining these two populations, as experimentally manipulating the position of a cell in the embryo can alter its polarity (41-43) and changing the polarity of a cell can in turn affect its position (31). From the 32-cell stage onward, these two cell populations have distinct developmental fates: cells on the outside of the embryo contribute to the TE lineage, while inside cells contribute to the inner cell mass (ICM), the group of cells that further diverges into the EPI and PE lineages (see below).

The processes of compaction, polarization, and asymmetric division have not been well studied in mammalian species other than the mouse. Studies of human preimplantation embryos developing in vitro indicate that their development closely resembles that of mouse embryos at the gross morphological level. One notable exception is the observation that compaction often occurs later in the human embryo than in the mouse, at the 16-cell stage (44-46), although it has also been reported to begin earlier, at the four- to eight-cell stage in some embryos (47). It is unclear how the different timing of compaction might affect polarization and asymmetric cell divisions in the human embryo.

\section{Figure 2}

Polarity in the mouse preimplantation embryo. (A) At the eight-cell stage, all blastomeres polarize along the axis of cell contact, forming outward, apical domains and inward-facing basolateral domains. (B) As the embryo grows from eight to 16 cells, blastomeres that divide parallel to the inside-outside axis produce two outside, polar cells. Blastomeres that divide perpendicular to the inside-outside axis produce one outside, polar daughter cell and one non-polar, inside daughter cell. This creates two populations of cells: outside, polar cells and inside, nonpolar cells. These two types of cell division also occur as the embryo grows from 16 to 32 cells.

Blastocoel formation. Starting at the 32-cell stage, as the outside cells of the embryo are becoming fully committed to the TE lineage $(48,49)$, a fluid-filled cavity known as the blastocoel begins to form (Figure 1). The presence of a blastocoel is essential for proper development of the ICM (49). During blastocoel formation water may enter the embryo via an osmotic gradient, as a result of $\mathrm{Na}^{+} / \mathrm{K}^{+}$ ATPases that produce an accumulation of $\mathrm{Na}^{+}$on the basolateral side of the TE (50). Water movement may also be facilitated by aquaporins, which are present in the TE and functional by the 32 -cell stage (51). Once it begins to form, maintenance of the blastocoel depends on the epithelial character of the TE. As early as one hour after compaction, and continuing for another full day, tight junction components such as occludin (52), zona occludens 1 (ZO-1) and ZO-2 $(53,54)$, and cingulin $(55,56)$ begin to assemble in outside cells, until functional tight junctions are fully formed by the 32 -cell stage $(52,54)$. These tight junctions form a seal, preventing water leakage. With the formation of the blastocoel at E3.5, the mouse embryo is now considered a blastocyst. It continues to mature for an additional 24 hours and is ready to implant into the uterine wall by E4.5. Although it has not been studied extensively, blastocoel formation in the human embryo appears to take place at approximately E4.5 (44).

\section{The early embryo: totipotent and developmentally flexible}

A unique characteristic of preimplantation mammalian development is that it is highly regulative. Early mammalian embryos are highly adaptable during the first three rounds of cleavage and can withstand changes such as the removal, addition, and rearrangement of blastomeres (57-59). Additionally, preimplantation embryos are able to develop in synthetic culture media for several days without showing obvious problems after being transferred back to the uterus. This remarkable flexibility has been used in the development of ARTs. Embryo culture is essential to the process of IVF, as zygotes are usually cultured for three days after fertilization in order to select embryos with the most normal-looking morphology to use for uterine transfer (60). In some cases, embryos are kept in culture for up to five days in order to improve their chances of successful implantation (61). The examination of embryos that have been cultured for longer periods provides even more opportunity to score for morphologically normal characteristics (62). However, recent studies have indicated that embryo culture may lead to aberrant expression of certain genes as a result of disruption to their epigenetic control mechanisms. This may be related to a possible increase in the frequency of syndromes associated with epigenetic defects, such as the overgrowth disorder Beckwith-Wiedemann syndrome, in children born as a result of ART $(63,64)$, although the incidence 
A

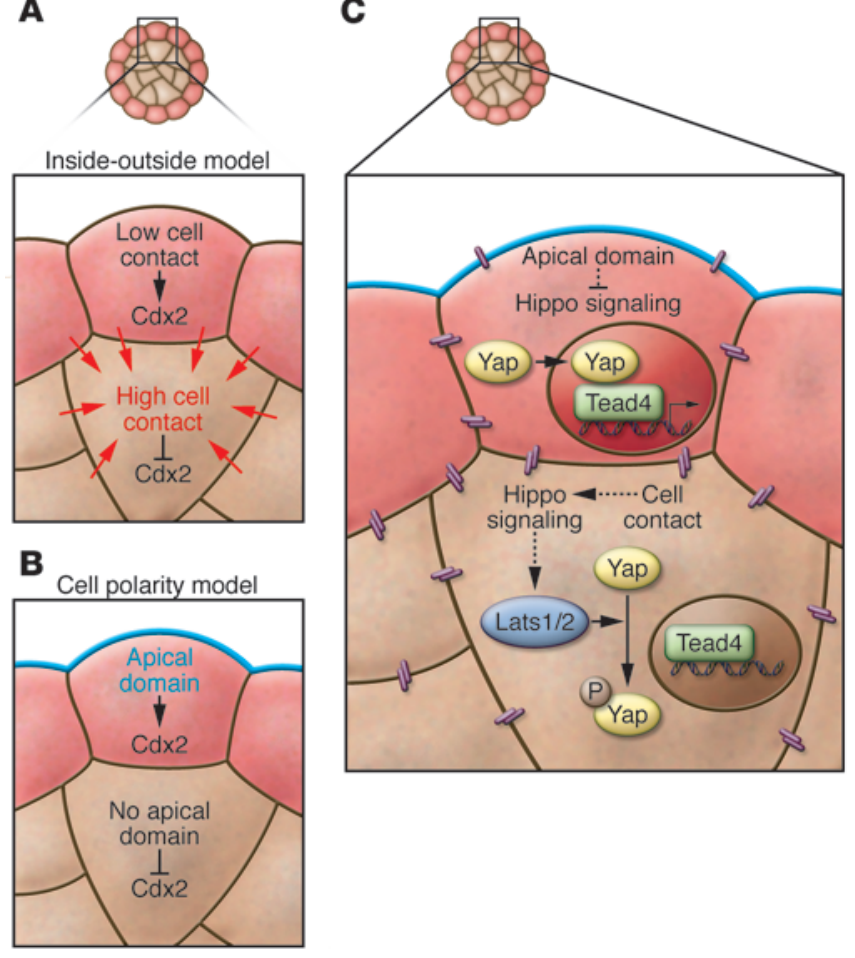

\section{Figure 3}

Models of TE specification in the mouse embryo. (A) According to the inside-outside model, cells on the inside and outside of the embryo receive different amounts of cell contact, and this is translated into differences in transcription factor expression. (B) According to the cell polarity model, the presence or absence of an apical domain is translated into differences in transcription factor expression. (C) After the eight-cell stage, active Lats $1 / 2$ kinases phosphorylate Yap in inside cells, preventing its movement into the nucleus. Without Yap, Tead4 cannot induce the expression of $C d x 2$. In outside cells, Lat1 and Lat2 are inactive and Yap is free to move into the nucleus, activating $C d x 2$. Increased cell-cell contact on the inside of the embryo may activate Lat1 and Lat2 via the Hippo signaling pathway, while some component of the apical domain may inhibit Hippo signaling and Lat1 and Lat2 activity in outside cells.

\section{The first lineage decision: segregation of the TE and ICM}

The first cell lineage to be specified in the preimplantation embryo is the TE. In the mouse, cells become fully committed to either the TE or ICM lineage during the 32-cell stage, at around E3.5. A major question in the field of preimplantation development is how this lineage decision is made. Based on the positions of TE and ICM cells in the mouse embryo and the discovery that changing the position of a cell can change its fate, early investigators developed the inside-outside model (59). According to this model, cells on the inside and outside of the embryo are exposed to different amounts of cell contact and to different microenvironments, and these differences become translated into cell fate (Figure 3). Later, the discovery of blastomere polarization, and of the ability of blastomeres to divide asymmetrically to produce both polar and nonpolar daughter cells, led to the establishment of the cell polarity model (39). According to this model, it is the inheritance of polarity that is translated into TE fate (Figure 3), although the exact molecular link between polarity and cell fate has remained unclear. One possibility is that some cell fate determinant(s) may be segregated specifically into, or out of, polarized cells during mitosis. One such determinant may be the TE-specifying transcription factor caudal type homeobox 2 (Cdx2) (see below), as Cdx2 mRNA appears to be localized to the apical domain of blastomeres at the eight-cell stage (71). It will be important to determine whether this apical localization does in fact result in preferential inheritance of Cdx2 mRNA to outside cells after the eight-cell stage, and whether this inheritance is reflected at the protein level, before conclusions can be drawn about the relationship between $C d x 2$ mRNA localization and TE specification. Regardless of whether TE specification is a result of cell position, cell polarity, or both, downstream transcription factors are most certainly required to translate these differences at the cellular level into differences in cell fate. Studying these transcription factors can help us gain insight into the cellular mechanisms that act upstream of them.

Transcription factor control of TE/ICM segregation. TE and ICM lineage segregation is controlled by a small group of transcription factors. Specifically, $\mathrm{Cd} \times 2$ is required for TE development, while the pluripotency markers octamer 3/4 (Oct4), Nanog, and SRYbox containing gene 2 (Sox2) are involved in establishing the ICM fate. In the mouse, $C d x 2$ is expressed at varying levels in all blastomeres starting at the eight-cell stage, but it becomes restricted to outside, future TE cells, prior to blastocyst formation (Figure 1) $(72,73)$. This variation in $\mathrm{Cdx} 2$ levels between individual blastomeres at the eight-cell stage may be a result of differences in the order and orientation of the cleavage divisions leading up to this 
stage (71). Embryos missing $C d x 2$ do form blastocysts initially, but the TE in these embryos loses its epithelial integrity and cannot differentiate further, resulting in death around the time of implantation (74). Oct4, Nanog, and Sox2 have expression patterns that are complementary to that of $C d x 2$ - they are also initially ubiquitous but become restricted to inside, future ICM cells, after the blastocyst has formed (75-78). Cdx2 becomes spatially restricted before Oct4, Nanog, and Sox2, indicating that it may be required to downregulate these three transcription factors in outside cells. In support of this notion, Oct4 and Nanog fail to be properly restricted in $C d x 2^{-/-}$embryos and are ectopically expressed in outside cells at the blastocyst stage (74). After they have been established, these expression patterns are reinforced by the later reciprocal repression of Cdx2 by Oct4, Nanog, and Sox $2(79,80)$, along with the autoregulation of Oct4 and $C d x 2(81,82)$.

Thus, the establishment of the TE and ICM lineages begins with the upregulation of $C d x 2$ in outside cells, followed by its downregulation of Oct4, Nanog, and Sox2 in these same cells. What leads to this initial upregulation of $C d x 2$ ? The answer appears to lie in two additional, recently identified transcription factors involved in TE specification, TEA domain family member 4 (Tead4) (83, 84) and Yes-associated protein 1 (Yap1; herein referred to as Yap) (85). Tead4 ${ }^{-/-}$embryos show a more severe phenotype than $C d x 2^{-/-}$ embryos, failing to form any blastocoel, and they do not express $C d x 2$. This indicates that Tead4 acts upstream of $C d x 2$ in TE specification. Tead 4 cannot act alone, however; it requires the additional presence of Yap, which acts as a transcriptional activator, to induce $C d x 2$ expression (85). Although Tead4 protein is similarly distributed in all cells of the embryo (83), Yap is only localized to the nuclei of outside cells; it is phosphorylated and excluded from the nuclei of inside cells beginning after the eight-cell stage (85). Thus, in outside cells, Yap and Tead 4 can cooperatively activate $C d x 2$ expression, but in inside cells, without the presence of Yap in the nucleus, Tead 4 is inactive and $C d x 2$ expression is silenced.

Hippo signaling and a new model for TE specification. The question now becomes what leads to the differential localization of Yap along the inside-outside axis of the embryo? Yap is a known downstream target of the Hippo signaling cascade in mammals, where its phosphorylation state and subcellular localization is regulated by the Hippo pathway members large tumor suppressor homolog 1 (Lats1) and Lats2, two closely related serine-threonine kinases that act redundantly $(86,87)$. A recent study showed that activated Lats1/2 can phosphorylate Yap in NIH-3T3 cells, preventing its movement into the nucleus (87). This relationship between Lats1/2 and Yap appears to be conserved in the preimplantation mouse embryo, as mouse embryos mutant for both Lats1 and Lats2 fail to restrict Yap to the cytoplasm of inside cells (85). As expected, the inside cells of Lats $1^{-/}$Lats $2^{-/-}$embryos show ectopic expression of $C d x 2$ (85).

This evidence that Hippo signaling can control $C d x 2$ expression has exciting implications for our understanding of TE specification. Notably, cell contact can lead to Hippo pathway activation in cultured cells $(85,87,88)$. The same may occur in the preimplantation embryo, where increased intercellular contacts between inside cells could activate Hippo signaling, resulting in Yap phosphorylation and nuclear exclusion specifically on the inside of the embryo. Indeed, when an E-cadherin-specific antibody is used to disrupt cell adhesion in cultured embryos, Yap is not excluded from nuclei of inside cells (85), suggesting that cell-cell contact is required to regulate its localization. This hypothesis is consistent with the original inside-outside model of TE specification, where cell position and cell-cell contact are the driving force behind cell fate.

It is also important to note that the relationship between cell position and Yap localization does not rule out a role for polarization in TE specification. It is possible that the polarized state is in some way inhibitory to the Hippo signaling cascade. In support of this, individual blastomeres that have been dissociated from eight-cell embryos and have become depolarized do not display nuclear-localized Yap, as would be the case if cell contact were the only factor regulating Hippo signaling (85). This could be explained if polarization was also involved, acting via a parallel pathway to silence Hippo signaling in outside cells. The recent studies of Hippo signaling and Yap localization have therefore led to a new model for TE specification, in which both cell position and cell polarization are required to direct cell fate (Figure 3 ). This type of model would allow embryos to capitalize on two distinct differences between inside and outside cells, polarity and position, resulting in a clear and unambiguous segregation between the TE and ICM lineages.

\section{The second lineage decision: segregation of the PE and EPI}

After specification of the TE, the ICM segregates into two lineages, the PE and the EPI. Considerably less is known about this second lineage decision than about the first. The PE forms as a monolayer of cells along the surface of the EPI that faces the blastocoel, while the EPI remains as a mass of cells between the PE and the TE (Figure 1). By E4.5 in the mouse, these two groups of cells are morphologically distinguishable, and the cells in each group are committed to their fates (89-91). Early models of PE/EPI specification were similar in concept to the inside-outside model of TE specification and held that this lineage decision was based on cell position. Due to differences in cell contact or microenvironment, cells on the outside of the ICM would take on a PE fate, while cells inside the ICM would become EPI. This model is based on the observation that in isolated mouse ICMs, as well as in mouse embryoid bodies (aggregates of cells derived from ES cells that resemble EPI cells), PE cells develop as an outer layer (92-94). An important postulate of this theory is that, prior to EPI/PE segregation, the ICM is a homogeneous population of bipotential cells. That is, any cell should be equally able to contribute to the PE or the EPI, and its eventual fate should be determined by where it happens to be located in the ICM. However, recent data have shown that this postulate is not entirely true. Lineage tracing using the E3.5 mouse ICM has shown that the majority of cells at this stage contribute to either the PE or the EPI (95), although some cells still retain the ability to contribute to both lineages $(95,96)$. Additionally, the position of a cell in the ICM does not always correlate with its later developmental fate (95). If cell position does not regulate PE/EPI lineage segregation, what does? In order to think about possible alternative models, it is necessary for us again to look at the transcription factors involved in this process.

Transcription factor control of PE/EPI specification. Two transcription factors, the closely related Gata family members Gata4 and Gata6, have been shown to be important for the specification of the mouse PE lineage. In mouse embryos mutant for either Gata4 or Gata6, the PE does form, but a later PE derivative, the visceral endoderm, does not $(97,98)$. The ability of these embryos to form $\mathrm{PE}$ may be due to some functional redundancy between Gata4 and 
A Position-dependent determination
E3.25
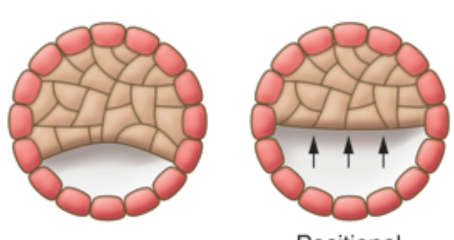

Positional
information

information

B Fgf/MAPK-dependent determination

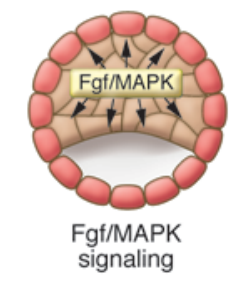

Gata6-positive cell

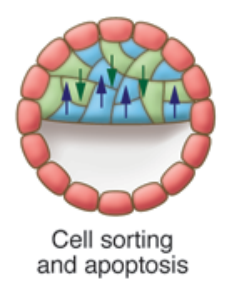

Nanog-positive cell
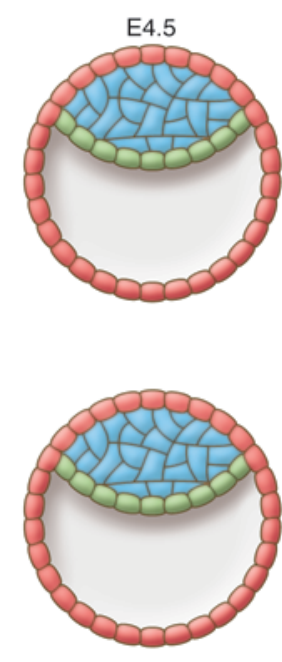

Cdx2-positive cell
Gata6 or to perdurance of maternal Gata proteins. In embryoid bodies made from either Gata4 ${ }^{-/-}$or $\mathrm{Gata6}^{-/-}$ES cells, PE-like cells fail to form on the outside surface $(98,99)$. Finally, when cells of the ICM are injected with a dominant-negative form of Gata6, they contribute significantly less to the PE than in wild-type situations (96). In contrast, overexpression of either gene is sufficient to transform ES cells into PE cells (100), and overexpression of Gata6 causes ICM cells to make a greater contribution to the PE when Wnt9A is also overexpressed in the same cells (96). In the EPI lineage, one important transcription factor is the pluripotency-promoting protein Nanog. It was originally thought that $\mathrm{Nanog}^{-/}$mouse embryos lacked EPI but were able to form PE (77). More recent work has shown that these mutants in fact lack both EPI and PE, but the observation that they contain small numbers of Gata4-positive cells has led to the hypothesis that the PE does form initially but cannot survive without support from the neighboring EPI, which does not form at all (101). Thus it appears that Gata4 and Gata6 are required to promote the PE fate and suppress the EPI fate, while the opposite is true for Nanog.

In the mouse ICM at E3.5, which corresponds to approximately the 32-cell stage, the patterns of Gata6 and Nanog expression are mutually exclusive such that most cells express either Gata6 or Nanog but rarely express both (Figure 4) $(95,102)$. This is consistent with the idea that most cells are committed to one or the other lineage by this stage. Notably, the two transcription factors are expressed in a random "salt and pepper" pattern that seems to be unrelated to cell position, suggesting that cells may be predisposed to either EPI or PE fate and then sort out into their appropriate positions.

Recent work has provided more detail to our understanding of PE/EPI segregation. First, it seems that prior to E3.5 in the mouse, many cells of the ICM coexpress both Nanog and Gata6 and gradually limit their expression to one transcription factor or the other as the ICM matures (102). This change in transcription factor expression may reflect the commitment of ICM cells to either the PE or EPI fate. Time-lapse imaging of cells expressing a second PE marker, Pdgfr $\alpha$, demonstrates that PE cells that begin inside the ICM at the early blastocyst stage undergo a considerable amount

\section{Figure 4}

Models of EPI/PE segregation in the mouse embryo. (A) In the position-dependent model, the mouse ICM at E3.5 is composed of a uniform population of bipotential cells, and those cells located on the outside surface of the ICM become PE due to some form of positional information. (B) In the Fgf/MAPK-dependent model, cells of the ICM are initially bipotential, but differences in Fgf signaling cause them to become either Nanog- or Gata6-positive by E3.5. These cells are distributed randomly in the ICM, and cell sorting combined with apoptosis results in the formation of organized PE and EPI layers by E4.5.

of movement to end up in the outside monolayer of PE cells by the late blastocyst stage (102). In addition, the Pdgfr $\alpha$-expressing cells that do not sort properly into the PE monolayer by the late blastocyst stage undergo apoptosis (102). Another group has shown that, in addition to the movement of inside cells to outside positions, cells can also move from the outside surface of the ICM to take up inside positions (96). This cell sorting likely relies on differences in the adhesive properties of PE and EPI cells, although the molecules responsible have yet to be identified. Finally, although the sorting of pre-committed cells likely plays a major role in the segregation of the PE and EPI, computer modeling of ICM development suggests that, as originally hypothesized, positional induction may also play a role in this process (96).

Fgf signaling and a new model for PE and EPI segregation. Embryos that lack Fgf signaling capacity due to mutation of the Fgf family member Fgf4, the receptor tyrosine kinase (RTK) Fgfr2, or the RTK adaptor protein Grb2 do not form PE (103-106). Additionally, Grb2-/- blastocysts do not express Gata6 (95). Together, these data suggest a model in which Fgf signaling is required to activate PE cell fate. But given that all ICM cells initially express EPI and PE markers, how is it that some cells respond to Fgf signaling and become PE, while others do not? One possibility is that ICM cells generated either by the eight-cell to 16-cell or the 16-cell to 32-cell round of cleavage differ in their Fgf responsiveness, as has been suggested previously (107). These two cell populations do differ in at least one known property, the possession of cytokeratin filaments (108), and could therefore differ in others. Careful lineage tracing to determine whether cells produced by either round of cleavage are more likely to contribute to the PE or EPI will help to address this hypothesis. Another possibility is that a more stochastic series of events, in which cells of the ICM fluctuate in their level of responsiveness to Fgf, may explain the heterogeneity of the ICM (102). Small initial differences in Fgf signaling and transcription factor expression may be reinforced by the mutual antagonism of Gata6 and Nanog $(109,110)$, leading to the eventual salt and pepper distribution of PE and EPI precursors.

\section{Human blastocyst lineage development and stem cell derivation}

Very little is known about the mechanistic aspects of lineage development in the early human embryo because of restrictions in the availability of and ethical issues surrounding experimentation in early human embryos. However, it is assumed that the processes of cleavage, compaction, and epithelial formation leading up to lineage segregation are similar between the mouse and the human, although the timing of these events may differ. Detailed expression studies of key lineage-specific genes in human embryos are still limited, although it is clear from mRNA expression studies that most of the primary lineage regulators, including OCT4, SOX2, NANOG, 
and $C D X 2$ are present in the human blastocyst $(111,112)$. However, only detailed temporal and spatial analysis of protein localization can really provide clues as to the conservation of the molecular events of lineage restriction. It has been shown that OCT4 protein is expressed throughout the human embryo, even beyond the initiation of blastocyst formation (113), and is not restricted to the ICM until six days after fertilization (114). In addition, $C D X 2$ does not begin to be expressed until E5.0, when the outer epithelium of the blastocyst is already formed (114). This is consistent with CDX2 playing a conserved role in suppressing OCT4 expression in TE, but it also suggests that the time of lineage restriction in relation to the initiation of blastocyst formation may be later in humans than mice. Is this related to the later onset of zygotic gene transcription in humans? What are the implications for the roles of putative upstream regulators such as apical polarity and Hippo signaling? All these questions remain unanswered. Of note are the observations that $C D X 2$ expression also appears to be limited to outside cells of porcine and bovine embryos at the blastocyst stage, and that OCT4 expression is not limited to the ICM in what appear to be fully expanded porcine blastocysts (115). This suggests that TE/ICM segregation may also occur somewhat later in other mammalian species than it does in mice.

Even less is known about the events of EPI versus PE segregation in the human embryo. A few reports on the localization of NANOG to the ICM in the human blastocyst mention in passing that not all cells express this marker $(113,116)$. Is this expression complementary to expression of PE markers? What is the exact timing of restriction of EPI and PE markers? Is FGF signaling important in establishing the lineages? These questions are important to answer because understanding the timing and pathways of this lineage restriction has relevance to the derivation of ES cells from human blastocysts. Studies in the mouse have indicated that EPI progenitors within the ICM give rise to ES cells and that blocking Fgf signaling can enhance EPI formation and promote ES derivation (117). Eggan and colleagues have shown that the efficiency of deriving human ES cells is highest six days after fertilization (114), which coincides with the time when OCT4 is restricted to the ICM and presumably when lineage restriction begins. Is this also the stage at which there is the greatest proportion of NANOG-expressing EPI cells?
Curiously, human ES cells do not resemble mouse ES cells in all their properties, although they share with EPI cells the expression of OCT4 and NANOG and the property of pluripotency. Interestingly, human ES cells require FGF signaling for maintenance of self-renewal in culture, whereas Fgf signaling in the mouse embryo promotes PE differentiation and, in mouse ES cells, promotes germ layer differentiation (118). This fundamental difference has led to suggestions that human ES cells are more similar to EPI cells of the early post-implantation stage mouse embryo (119-121). However, it remains unclear why isolated human ICMs would progress down this pathway in culture. More detailed investigation of the interactions between signaling pathways and transcription factor networks during human preimplantation development will help to address this question. One study has examined the induction of several key transcription factors after treatment of human preimplantation embryos with the growth factors IGF-1, leukemia inhibitory factor (LIF), and heparin-binding EGF-like growth factor (116), but more study is needed in this area to better inform our understanding of the lineage state of human ES cells, to improve the efficiency of their derivation, and to provide a rational comparison to newly derived induced pluripotent stem cells. It will also provide better methods for culturing human embryos for ART. Ethical restrictions in different jurisdictions may limit some of the approaches that can be used, but a strong case for the importance of understanding the similarities and differences between mouse and human embryos can now be made.

\section{Acknowledgments}

We thank Peter Rugg-Gunn for critical reading of the manuscript. Work in the Rossant lab is supported by the Canadian Institutes of Health Research.

Address correspondence to: Janet Rossant, Program in Developmental and Stem Cell Biology, Hospital for Sick Children Research Institute, MARS Building, Toronto Medical Discovery Tower, 101 College St., Toronto, Ontario M5G 1L7, Canada. Phone: 416.813.7929; Fax: 416.813.5085; E-mail: janet.rossant@sickkids.ca.
1. Bacharova R. Gene expression during oogenesis and oocyte development in mammals. Dev Biol (NY 1985). 1985;1:453-524.

2. Aoki F, Worrad DM, Schultz RM. Regulation of transcriptional activity during the first and second cell cycles in the preimplantation mouse embryo. Dev Biol. 1997;181(2):296-307.

3. Hamatani T, Carter MG, Sharov AA, Ko MS Dynamics of global gene expression changes during mouse preimplantation development. Dev Cell. 2004;6(1):117-131.

4. Bachvarova R, Moy K. Autoradiographic studies on the distribution of labeled maternal RNA in early mouse embryos. J Exp Zool. 1985;233(3):397-403.

5. Paynton BV, Rempel R, Bachvarova R. Changes in state of adenylation and time course of degradation of maternal mRNAs during oocyte maturation and early embryonic development in the mouse. Dev Biol. 1988;129(2):304-314.

6 . Braude P, Bolton V, Moore S. Human gene expression first occurs between the four- and eight-cell stages of preimplantation development. Nature. 1988;332(6163):459-461.

7. Larue L, Ohsugi M, Hirchenhain J, Kemler R. E-cadherin null mutant embryos fail to form a trophectoderm epithelium. Proc Natl Acad Sci US A. 1994;91(17):8263-8267.
8. Riethmacher D, Brinkmann V, Birchmeier C. A targeted mutation in the mouse E-cadherin gene results in defective preimplantation development. Proc Natl Acad Sci U S A. 1995;92(3):855-859.

9. Vestweber D, Gossler A, Boller K, Kemler R. Expression and distribution of cell adhesion molecule uvomorulin in mouse preimplantation embryos. Dev Biol. 1987;124(2):451-456.

10. Ducibella T, Ukena T, Karnovsky M, Anderson E. Changes in cell surface and cortical cytoplasmic organization during early embryogenesis in the preimplantation mouse embryo. J Cell Biol. 1977;74(1):153-167.

11. Hyafil F, Morello D, Babinet C, Jacob F. A cell surface glycoprotein involved in the compaction of embryonal carcinoma cells and cleavage stage embryos. Cell. 1980;21(3):927-934.

12. Vestweber D, Kemler R. Rabbit antiserum against a purified surface glycoprotein decompacts mouse preimplantation embryos and reacts with specific adult tissues. Exp Cell Res. 1984;152(1):169-178.

13. De Vries WN, et al. Maternal beta-catenin and E-cadherin in mouse development. Development. 2004;131(18):4435-4445.

14. Ohsugi M, et al. Expression and cell membrane localization of catenins during mouse preimplantation development. Dev Dyn. 1996;206(4):391-402.
15. Kidder GM, McLachlin JR. Timing of transcription and protein synthesis underlying morphogenesis in preimplantation mouse embryos. Dev Biol. 1985;112(2):265-275.

16. Levy JB, Johnson MH, Goodall H, Maro B. The timing of compaction: control of a major developmental transition in mouse early embryogenesis. J Embryol Exp Morphol. 1986;95:213-237.

17. Ohsugi M, Ohsawa T, Semba R. Similar responses to pharmacological agents of 1,2-OAG-induced compaction-like adhesion of two-cell mouse embryo to physiological compaction. J Exp Zool. 1993;265(5):604-608.

18. Winkel GK, Ferguson JE, Takeichi M, Nuccitelli R. Activation of protein kinase $\mathrm{C}$ triggers premature compaction in the four-cell stage mouse embryo. Dev Biol. 1990;138(1):1-15.

19. Clayton L, Stinchcombe SV, Johnson MH. Cell surface localisation and stability of uvomorulin during early mouse development. Zygote. 1993;1(4):333-344.

20. Pauken CM, Capco DG. Regulation of cell adhesion during embryonic compaction of mammalian embryos: roles for PKC and beta-catenin. Mol Reprod Dev. 1999;54(2):135-144.

21. Clayton L, Hall A, Johnson MH. A role for Rho-like GTPases in the polarisation of mouse eight-cell 
blastomeres. Dev Biol. 1999;205(2):322-331.

22. Natale DR, Watson AJ. Rac-1 and IQGAP are potential regulators of E-cadherin-catenin interactions during murine preimplantation development. Gene Expr Patterns. 2002;2(1-2):17-22.

23. Kuroda S, Fukata M, Nakagawa M, Kaibuchi K. Cdc42, Rac1, and their effector IQGAP1 as molecular switches for cadherin-mediated cell-cell adhesion. Biochem Biophys Res Commun. 1999;262(1):1-6.

24. Watson AJ, Natale DR, Barcroft LC. Molecular regulation of blastocyst formation. Anim Reprod Sci. 2004;82-83:583-592

25. Reeve WJ, Kelly FP. Nuclear position in the cells of the mouse early embryo. J Embryol Exp Morphol. 1983;75:117-139.

26. Fleming TP, Pickering SJ. Maturation and polarization of the endocytotic system in outside blastomeres during mouse preimplantation development. J Embryol Exp Morphol. 1985;89:175-208.

27. Houliston E, Maro B. Posttranslational modification of distinct microtubule subpopulations during cell polarization and differentiation in the mouse preimplantation embryo. J Cell Biol. 1989;108(2):543-551

28. Johnson MH, Maro B. The distribution of cytoplasmic actin in mouse 8-cell blastomeres. J Embryol Exp Morphol. 1984;82:97-117.

29. Fleming TP, Pickering SJ, Qasim F, Maro B. The generation of cell surface polarity in mouse 8-cell blastomeres: the role of cortical microfilaments analysed using cytochalasin D. J Embryol Exp Morphol. 1986;95:169-191.

30. Louvet S, Aghion J, Santa-Maria A, Mangeat P, Maro B. Ezrin becomes restricted to outer cells following asymmetrical division in the preimplantation mouse embryo. Dev Biol. 1996;177(2):568-579.

31. Plusa B, et al. Downregulation of Par3 and aPKC function directs cells towards the ICM in the preimplantation mouse embryo. J Cell Sci. 2005;118(Pt 3):505-515

32. Vinot $\mathrm{S}$, et al. Asymmetric distribution of PAR proteins in the mouse embryo begins at the 8-cell stage during compaction. Dev Biol. 2005;282(2):307-319.

33. Pauken CM, Capco DG. The expression and stagespecific localization of protein kinase $\mathrm{C}$ isotypes during mouse preimplantation development. Dev Biol. 2000;223(2):411-421.

34. Johnson $\mathrm{MH}$, Ziomek CA. Induction of polarity in mouse 8-cell blastomeres: specificity, geometry, and stability. J Cell Biol. 1981;91(1):303-308.

35. Ziomek CA, Johnson MH. Cell surface interaction induces polarization of mouse 8-cell blastomeres at compaction. Cell. 1980;21(3):935-942.

36. Houliston E, Pickering SJ, Maro B. Alternative routes for the establishment of surface polarity during compaction of the mouse embryo. Dev Biol. 1989;134(2):342-350

37. Johnson MH, Maro B, Takeichi M. The role of cell adhesion in the synchronization and orientation of polarization in 8-cell mouse blastomeres. J Embryol Exp Morphol. 1986;93:239-255.

38. Suzuki A, Ohno S. The PAR-aPKC system: lessons in polarity. J Cell Sci. 2006;119(Pt 6):979-987.

39. Johnson MH, Ziomek CA. The foundation of two distinct cell lineages within the mouse morula. Cell. 1981;24(1):71-80.

40. Sutherland AE, Speed TP, Calarco PG. Inner cell allocation in the mouse morula: the role of oriented division during fourth cleavage. Dev Biol. 1990;137(1):13-25

41. Handyside AH. Time of commitment of inside cells isolated from preimplantation mouse embryos. J Embryol Exp Morphol. 1978;45:37-53.

42. Spindle AI. Trophoblast regeneration by inner cell masses isolated from cultured mouse embryos. J Exp Zool. 1978;203:483-489.

43. Rossant J, Lis WT. Potential of isloated mouse inner cell masses to form trophectoderm deriva- tives in vivo. Dev Biol. 1979;70(1):255-261.

44. Edwards RG, Purdy JM, Steptoe PC, Walters DE. The growth of human preimplantation embryos in vitro. Am J Obstet Gynecol. 1981;141(4):408-416.

45. Steptoe PC, Edwards RG, Purdy JM. Human blastocysts grown in culture. Nature. 1971; 229(5280):132-133.

46. Trounson AO, Mohr LR, Wood C, Leeton JF. Effect of delayed insemination on in-vitro fertilization, culture and transfer of human embryos. J Reprod Fertil. 1982;64(2):285-294.

47. Desai NN, Goldstein J, Rowland DY, Goldfarb JM Morphological evaluation of human embryos and derivation of an embryo quality scoring system specific for day 3 embryos: a preliminary study. Hum Reprod. 2000;15(10):2190-2196.

48. Dyce J, George M, Goodall H, Fleming TP. Do trophectoderm and inner cell mass cells in the mouse blastocyst maintain discrete lineages? Devel opment. 1987;100(4):685-698.

49. Pedersen RA, Wu K, Balakier H. Origin of the inner cell mass in mouse embryos: cell lineage analysis by microinjection. Dev Biol. 1986;117(2):581-595.

50. Watson AJ, Barcroft LC. Regulation of blastocyst formation. Front Biosci. 2001;6:D708-D730.

51. Barcroft LC, Offenberg H, Thomsen P, Watson AJ. Aquaporin proteins in murine trophectoderm mediate transepithelial water movements during cavitation. Dev Biol. 2003;256(2):342-354.

52. Sheth B, et al. Differentiation of the epithelial apical junctional complex during mouse preimplantation development: a role for rab13 in the early maturation of the tight junction. Mech Dev. 2000;97(1-2):93-104.

53. Fleming TP, McConnell J, Johnson MH, Stevenson BR. Development of tight junctions de novo in the mouse early embryo: control of assembly of the tight junction-specific protein, ZO-1. J Cell Biol. 1989;108(4):1407-1418.

54. Sheth B, et al. Tight junction assembly during mouse blastocyst formation is regulated by late expression of ZO-1 alpha+ isoform. Development. 1997;124(10):2027-2037.

55. Fleming TP, Hay M, Javed Q, Citi S. Localisation of tight junction protein cingulin is temporally and spatially regulated during early mouse development. Development. 1993;117(3):1135-1144.

56. Javed Q, Fleming TP, Hay M, Citi S. Tight junction protein cingulin is expressed by maternal and embryonic genomes during early mouse development. Development. 1993;117(3):1145-1151.

57. Hillman N, Sherman MI, Graham C. The effect of spatial arrangement on cell determination during mouse development. J Embryol Exp Morphol. 1972;28(2):263-278.

58. Hogan B, Tilly R. In vitro development of inner cell masses isolated immunosurgically from mouse blastocysts. II. Inner cell masses from 3.5to 4.0-day p.c. blastocysts. J Embryol Exp Morphol. 1978;45:107-121.

59. Tarkowski AK, Wroblewska J. Development of blastomeres of mouse eggs isolated at the 4- and 8-cell stage. J Embryol Exp Morphol. 1967;18(1):155-180.

60. Goldberg JM, Falcone T, Attaran M. In vitro fertilization update. Cleve Clin J Med. 2007;74(5):329-338.

61. Quea G, Romero K, Garcia-Velasco JA. Extended embryo culture to increase implantation rate. Reprod Biomed Online. 2007;14(3):375-383.

62. Gardner DK, Lane M, Stevens J, Schlenker T, Schoolcraft WB. Blastocyst score affects implantation and pregnancy outcome: towards a single blastocyst transfer. Fertil Steril. 2000;73(6):1155-1158.

63. Gicquel C, et al. In vitro fertilization may increase the risk of Beckwith-Wiedemann syndrome related to the abnormal imprinting of the KCN1OT gene. Am J Hum Genet. 2003;72(5):1338-1341.

64. Maher ER, et al. Beckwith-Wiedemann syndrome and assisted reproduction technology (ART). J Med Genet. 2003;40(1):62-64.
65. Halliday J, Oke K, Breheny S, Algar E, Amor DJ. Beckwith-Wiedemann Syndrome and ICF: A case-control study. Am J Hum Genet. 2004;75(3):526-528.

66. Bowdin S, et al. A survey of assisted reproductive technology births and imprinting disorders. Hum Reprod. 2007;22(12):3237-3240.

67. Kearns WG, et al. Preimplantation genetic diagnosis and screening. Semin Reprod Med. 2005; 23(4):336-347.

68. Piotrowska-Nitsche K, Perea-Gomez A, Haraguchi S, Zernicka-Goetz M. Four-cell stage mouse blastomeres have different developmental properties. Development. 2005;132(3):479-490.

69. Staun-Raum E, Shalev E. Human trophoblast function during the implantation process. Reprod Biol Endocrinol. 2005;3:56

70. Macklon NS, Geraedts JPM, Fauser BCJM. Conception to ongoing pregnancy: the 'black box' of early pregnancy loss. Hum Reprod Update. 2002;8(4):333-343.

71. Jedrusik A, et al. Role of $\mathrm{Cdx} 2$ and cell polarity in cell allocation and specification of trophectoderm and inner cell mass in the mouse embryo. Genes Dev. 2008;22(19):2692-2706.

72. Dietrich JE, Hiiragi T. Stochastic patterning in the mouse pre-implantation embryo. Development. 2007;134(23):4219-4231.

73. Ralston A, Rossant J. Cdx2 acts downstream of cell polarization to cell-autonomously promote trophectoderm fate in the early mouse embryo. Dev Biol. 2008;313(2):614-629.

74. Strumpf D, et al. Cdx2 is required for correct cell fate specification and differentiation of trophectoderm in the mouse blastocyst. Development. 2005;132(9):2093-2102.

75. Avilion AA, et al. Multipotent cell lineages in early mouse development depend on SOX2 function. Genes Dev. 2003;17(1):126-140.

76. Chambers I, et al. Functional expression cloning of Nanog, a pluripotency sustaining factor in embryonic stem cells. Cell. 2003;113(5):643-655.

77. Mitsui K, et al. The homeoprotein Nanog is required for maintenance of pluripotency in mouse epiblast and ES cells. Cell. 2003;113(5):631-642.

78. Palmieri SL, Peter W, Hess H, Scholer HR. Oct-4 transcription factor is differentially expressed in the mouse embryo during establishment of the first two extraembryonic cell lineages involved in implantation. Dev Biol. 1994;166(1):259-267.

79. Boyer LA, et al. Core transcriptional regulatory circuitry in human embryonic stem cells. Cell. 2005;122(6):947-956.

80. Loh YH, et al. The Oct4 and Nanog transcription network regulates pluripotency in mouse embryonic stem cells. Nat Genet. 2006;38(4):431-440.

81. Beland $\mathrm{M}$, et al. Cdx1 autoregulation is governed by a novel Cdx1-LEF1 transcription complex. Mol Cell Biol. 2004;24(11):5028-5038.

82. Chew JL, et al. Reciprocal transcriptional regulation of Pou5f1 and Sox 2 via the Oct4/Sox 2 complex in embryonic stem cells. Mol Cell Biol. 2005;25(14):6031-6046

83. Nishioka N, et al. Tead 4 is required for specification of trophectoderm in pre-implantation mouse embryos. Mech Dev. 2008;125(3-4):270-283.

84. Yagi $\mathrm{R}$, et al. Transcription factor TEAD4 specifies the trophectoderm lineage at the beginning of mammalian development. Development. 2007;134(21):3827-3836

85. Nishioka N, et al. The Hippo signaling pathway components Lats and Yap pattern Tead4 activity to distinguish mouse trophectoderm from inner cell mass. Dev Cell. 2009;16(3):398-410.

86. Reddy BV, Irvine KD. The Fat and Warts signaling pathways: new insights into their regulation, mechanism and conservation. Development. 2008;135(17):2827-2838

87. Zhao B, et al. TEAD mediates YAP-dependent 
gene induction and growth control. Genes Dev. 2008;22(14):1962-1971.

88. Ota M, Sasaki H. Mammalian Tead proteins regulate cell proliferation and contact inhibition as transcriptional mediators of Hippo signaling. Development. 2008;135(24):4059-4069.

89. Gardner RL. Investigation of cell lineage and differentiation in the extraembryonic endoderm of the mouse embryo. J Embryol Exp Morphol. 1982;68:175-198.

90. Gardner RL. An in situ cell marker for clonal analysis of development of the extraembryonic endoderm in the mouse. J Embryol Exp Morphol. 1984;80:251-288.

91. Gardner RL, Rossant J. Investigation of the fate of 4-5 day post-coitum mouse inner cell mass cells by blastocyst injection. J Embryol Exp Morphol. 1979;52:141-152.

92. Becker S, Casanova J, Grabel L. Localization of endoderm-specific mRNAs in differentiating F9 embryoid bodies. Mech Dev. 1992;37(1-2):3-12.

93. Dziadek M. Cell differentiation in isolated inner cell masses of mouse blastocysts in vitro: onset of specific gene expression. J Embryol Exp Morphol. 1979;53:367-379.

94. Murray P, Edgar D. The regulation of embryonic stem cell differentiation by leukaemia inhibitory factor (LIF). Differentiation. 2001;68(4-5):227-234.

95. Chazaud C, Yamanaka Y, Pawson T, Rossant J. Early lineage segregation between epiblast and primitive endoderm in mouse blastocysts through the Grb2MAPK pathway. Dev Cell. 2006;10(5):615-624.

96. Meilhac SM, et al. Active cell movements coupled to positional induction are involved in lineage segregation in the mouse blastocyst. Dev Biol. 2009;331(2):210-221.

97. Koutsourakis M, Langeveld A, Patient R, Beddington $\mathrm{R}$, Grosveld F. The transcription factor GATA6 is essential for early extraembryonic development. Development. 1999;126:723-732.

98. Morrisey EE, et al. GATA6 regulates HNF4 and is required for differentiation of visceral endoderm in the mouse embryo. Genes Dev.
1998;12(22):3579-3590.

99. Soudais C, et al. Targeted mutagenesis of the transcription factor GATA-4 gene in mouse embryonic stem cells disrupts visceral endoderm differentiation in vitro. Development. 1995;121(11):3877-3888.

100.Fujikura J, et al. Differentiation of embryonic stem cells is induced by GATA factors. Genes Dev. 2002;16(7):784-789.

101. Silva J, et al. Nanog is the gateway to the pluripotent ground state. Cell. 2009;138(4):722-737.

102.Plusa B, Piliszek A, Frankenberg S, Artus J, Hadjantonakis AK. Distinct sequential cell behaviours direct primitive endoderm formation in the mouse blastocyst. Development. 2008;135(18):3081-3091.

103.Arman E, Haffner-Krausz R, Chen Y, Heath JK, Lonai P. Targeted disruption of fibroblast growth factor (FGF) receptor 2 suggests a role for FGF signaling in pregastrulation mammalian development. Proc Natl Acad Sci U S A. 1998;95(9):5082-5087.

104. Cheng AM, et al. Mammalian Grb2 regulates multiple steps in embryonic development and malignant transformation. Cell. 1998;95(6):793-803.

105. Feldman B, Poueymirou W, Papaioannou VE, DeChiara TM, Goldfarb M. Requirement of FGF-4 for postimplantation mouse development. Science. 1995;267(5195):246-249.

106.Wilder PJ, et al. Inactivation of the FGF-4 gene in embryonic stem cells alters the growth and/or the survival of their early differentiated progeny. Dev Biol. 1997;192(2):614-629.

107. Rossant J, Chasaud C, Yamanaka Y. Lineage allocation and asymmetries in the early mouse embryo. Philos Trans R Soc Lond B Biol Sci. 2003;358(1436):1341-1348.

108. Chisholm JC, Houliston E. Cytokeratin filament assembly in the preimplantation mouse embryo. Development. 1987;101(3):565-582.

109. Hamazaki T, Kehoe SM, Nakano T, Terada $\mathrm{N}$. The Grb2/Mek pathway represses Nanog in murine embryonic stem cells. Mol Cell Biol. 2006;26(20):7539-7549.

110.Singh AM, Hamazaki T, Hankowski KE, Tera- da N. A heterogeneous expression pattern for Nanog in embryonic stem cells. Stem Cells. 2007;25(10):2534-2542.

111.Hansis C, Grifo JA, Krey LC. Oct-4 expression in inner cell mass and trophectoderm of human blastocysts. Mol Hum Reprod. 2000;6(11):999-1004.

112.Adjaye J, et al. Primary differentiation in the human blastocyst: comparative molecular portraits of inner cell mass and trophectoderm cells. Stem Cells. 2005;23(10):1514-1525.

113.Cauffman G, De Rycke M, Sermon K, Liebaers I, Van de Velde H. Markers that define stemness in ESC are unable to identify the totipotent cells in human preimplantation embryos. Hum Reprod. 2009;24(1):63-70.

114. Chen AE, et al. Optimal timing of inner cell mass isolation increases the efficiency of human embryonic stem cell derivation and allows generation of sibling cell lines. Cell Stem Cell. 2009;4(2):103-106.

115.Kuijk EW, et al. Differences in early lineage segregation between mammals. Dev Dyn. 2008;237(4):918-927.

116. Kimber SJ, et al. Expression of genes involved in early cell fate decisions in human embryos and their regulation by growth factors. Reproduction. 2008;135(5):635-647.

117. Nichols J, Silva J, Roode M, Smith A. Suppression of Erk signalling promotes ground state pluripotency in the mouse embryo. Development. 2009;136(19):3215-3222.

118. Kunath T, et al. FGF stimulation of the Erk $1 / 2$ signalling cascade triggers transition of pluripotent embryonic stem cells from self-renewal to lineage commitment. Development. 2007;134(16):2895-2902.

119. Brons IG, et al. Derivation of pluripotent epiblast stem cells from mammalian embryos. Nature. 2007;448(7150):191-195.

120.Tesar PJ, et al. New cell lines from mouse epiblast share defining features with human embryonic stem cells. Nature. 2007;448(7150):196-199.

121. Rossant J. Stem cells and early lineage development. Cell. 2008;132(4):527-531. 